\title{
Promídia: produção de vídeos digitais no contexto educacional
}

\author{
Ariel Vargas \\ Instituto de Computação (IC) \\ Universidade Estadual de Campinas (UNICAMP) \\ vargas@ic.unicamp.br \\ Heloísa Vieira da Rocha \\ Instituto de Computação (IC) \\ Universidade Estadual de Campinas (UNICAMP) \\ heloisa@ic.unicamp.br \\ Fernanda Maria Pereira Freire \\ Núcleo de Informática Aplicada à Educação (NIED) \\ Universidade Estadual de Campinas (UNICAMP) \\ ffreire@ unicamp.br
}

\section{Resumo}

Nos dias de hoje a produção de vídeos digitais é uma atividade muito popular, principalmente entre crianças e adolescentes, como se observa pelo sucesso que fazem os sites que permitem disponibilizar vídeos na Internet. Apesar de geralmente ser desenvolvida visando o lazer e o entretenimento essa atividade tem grande potencial educacional. Tal potencial pode ser melhor explorado se levarmos em conta as características das atividades que compõem o processo de produção de vídeos propriamente dito, tais como: desenvolvimento da sinopse, elaboração do roteiro, elaboração do storyboard, edição, etc. Essas atividades, no entanto,requerem softwares que possam dar suporte a sua execução e, em um contexto educacional, possam favorecer a visão geral de todo o processo de produção. Com o objetivo de favorecer e estimular a produção de vídeos como atividade educacional desenvolvemos o protótipo do Promídia que tem como objetivos: (i) auxiliar seus usuários na criação e elaboração das principais etapas do processo de produção de vídeos, (ii) favorecer a visão global e a compreensão de todo o processo. Dois testes foram realizados com o Promídia, com usuários com perfis diferentes, para se observar/analisar tanto questões de usabilidade quanto questões educacionais. Os resultados mostraram uma excelente aceitação do protótipo e confirmaram o potencial da produção de vídeo como atividade de ensino-aprendizagem.

Palavras-Chave: Software Educacional, Produção de Vídeos Digitais, Educação, Multimídia

\begin{abstract}
Nowadays, digital video production is a popular activity, mainly among young people. It can be observed by the success of WEB sites within people can share videos. Although the activity is commonly developed for fun and entertainment, but is has a big educational power. Its educational power can be explored if some activities into production process are in mind, like synopsis developing, screenplay writing, storyboard and edition developing, etc. Although, that activities need software support to be done, and in an education context this kind of software should enable a global view and whole process comprehension by users. Thus, Promídia prototype was developed to encourage video production and help its users in developing the main activities in video production process also giving them the whole process view. Two tests were which users used Promídia to develop a video production. The results of the tests point to the educational power of the activity.
\end{abstract}

Keywords: Educational Software, Digital Video Production, Learning, Multimedia 


\section{Introdução}

A produção de vídeos digitais de curta duração tornou-se uma atividade muito popular nos dias de hoje. Páginas que permitem assistir e/ou disponibilizar vídeos estão entre as mais acessadas na Internet. Dentre os usuários mais interessados nesse tipo de atividade estão crianças e adolescentes, um público que crescentemente se identifica muito com esse tipo de mídia. Dentre os usuários mais interessados nesse tipo de atividade estão crianças e adolescentes, um público que crescentemente se identifica muito com esse tipo de mídia dado seu caráter altamente motivacional como indicam os estudos de Shewbridge \& Berge (2004) e Ellis et al. (2004).

Apesar de ser geralmente associada ao lazer e entretenimento a produção de vídeos digitais pode ser utilizada como atividade de ensino e aprendizagem com vasto potencial educacional ainda a ser explorado. A literatura especializada aponta vários benefícios educacionais, dentre eles:

- Desenvolvimento do pensamento crítico - Segundo Shewbridge \& Berge (2004) as atividades de produção de vídeos podem servir para formar, além de produtores, consumidores mais "informados". Tais atividades tendem a desenvolver a base analítica necessária para que os alunos se tornem consumidores mais observadores e críticos em relação aos produtos desse tipo de mídia.

- Promoção da expressão e da comunicação - Segundo Moran (1995) a produção de vídeos no contexto educacional pode ser utilizada como um meio de expressão e de comunicação. Monteiro (2006) observa que, em geral, os alunos envolvidos nesse tipo de atividade tendem a superar a timidez e ampliar seu espaço discursivo.

- Favorecimento de uma visão interdisciplinar - Potencialmente, o processo de produção de vídeos promove uma atividade em que os alunos aprendem de forma interdisciplinar, flexível e prática, e não apenas teórica. Segundo Martiani (1998), a produção de vídeos no contexto da escola, pode integrar-se a diferentes disciplinas, envolvendo atividades de comunicação em torno de diversos assuntos ou temas explorados, seja no âmbito do ensino fundamental, médio ou superior.

- Integração de diferentes capacidades e inteligências - Martiani (1998) afirma que a produção de vídeos é uma experiência que mobiliza diversas habilidades, aptidões ou inteligências dos alunos envolvidos no processo, como: inteligência lingüística, lógicomatemática, musical, espacial, corporal-sinestésica, inter-pessoal e intra-pessoal.

- Valorização do trabalho em grupo - Por se tratar de um trabalho que, em geral, é feito por uma equipe, a produção de vídeos valoriza a interação social, a participação e a iniciativa dos alunos, já que demanda boa convivência entre seus integrantes. Também promove o respeito à opinião do outro e o sentimento de co-responsabilidade (Shewbridge \& Berge, 2004).

Supomos, no entanto, que esses ganhos educacionais podem ser enriquecidos se a produção de vídeos não se restringir às filmagens e englobar - tal como ocorre em contextos profissionais - aquelas atividades que dizem respeito à pré-produção e à pós-produção. Pensando nisso apresentamos no item 2 as atividades que caracterizam todo o processo de produção de vídeos e que orientaram o desenvolvimento do protótipo do Promídia, descrito no item 3 . Os itens 3 e 4 apresentam, respectivamente, os testes realizados com usuários e os resultados obtidos. Finalmente, nos itens 5 e 6 apresentamos algumas considerações sobre o desenvolvimento e a utilização do Promídia com finalidades educacionais e indicamos algumas direções para o prosseguimento deste trabalho.

\section{O processo de produção de vídeos}

Segundo Kindem \& Musburger (1997) o processo de produção de um vídeo tem, basicamente, três etapas: 
Pré-produção: Consiste na preparação, planejamento e projeto do vídeo a ser produzido. Essa etapa abrange todas as demais atividades que serão realizadas, desde a concepção da idéia inicial até a filmagem:

- Sinopse ou storyline: resumo geral do que vai ser exibido no vídeo;

- Argumento: passo intermediário entre a sinopse e o roteiro cujo objetivo é descrever, de forma breve, como se desenvolverá a ação.

- Roteiro: detalhamento de tudo o que vai acontecer no vídeo. O roteiro tem uma linguagem própria - que se destina a orientar a equipe de produção nas filmagens - e divide o vídeo em cenas com o objetivo de informar - textualmente - o leitor a respeito daquilo que o espectador verá/ouvirá no vídeo.

- Storyboard: é a representação das cenas do roteiro em forma de desenhos seqüenciais, semelhante a uma história em quadrinhos. Tem o objetivo de tornar mais fácil, para a equipe de produção, a visualização das cenas antes que sejam gravadas.

Produção: Esta é a etapa em que são feitas as filmagens das cenas que compõem o vídeo. As filmagens são realizadas em tomadas, isto é, intervalos de tempo entre o início e o término de cada gravação. Uma cena, portanto, é composta por um conjunto de tomadas, e um vídeo é composto por um conjunto de cenas. Depois de terminadas as filmagens começa a pósprodução do vídeo.

Pós-Produção: Essa última etapa recobre todas as atividades até então realizadas para a finalização do vídeo quando então se faz a edição e a organização das tomadas gravadas para composição das cenas e do vídeo como um todo.

\subsection{Ferramentas de apoio à produção de vídeos}

Para apoiar o desenvolvimento das etapas da produção de vídeos descritas no item anterior existem diversas ferramentas computacionais no mercado, como por exemplo: o Final Draft (2006) e o Movie Magic Screen Whiter (2006) para a produção de roteiros; o Storyboard Quick (2006) e o SpringBoard (2006) para a produção de storyboards e o Adobe Premiere (2006), Windows Movie Maker (2006) e o iMovie (2006) para a edição de vídeos.

Todas essas ferramentas são profissionais e têm, pelo menos, os recursos básicos para as atividades as quais se propõem. Apesar da qualidade dessas ferramentas cada uma delas contempla apenas uma das etapas da produção de vídeos já que não são integradas entre si.

No contexto educacional, porém, é desejável que os alunos tenham uma visão geral de todo o processo de modo a facilitar a navegação entre as suas diferentes etapas de modo a ajustálas/melhorá-las sempre que necessário. Conhecer o processo de produção de vídeos - enquanto se produz um - pode auxiliar no delineamento de todo o projeto (incluindo a seleção do tema) e contribuir para que os alunos ganhem autonomia em relação ao que estão produzindo. Por essas razões acreditamos que uma ferramenta de suporte à produção de vídeos com finalidades educacionais deve, além de apoiar a produção de vídeos propriamente dito, prover recursos que favoreçam o entendimento e o aprendizado de todo o processo envolvido.

Um dos primeiros softwares educacionais voltados para a produção de vídeos relatado na literatura é o Movie Authoring and Design (MAD) (Rosenthal \& Baecker, 1994), (Baecker et. al, 1996), (Posner et. al, 1997), (Baecker \& Posner, 1999). O MAD foi desenvolvido com o objetivo de auxiliar crianças na produção de vídeos e embora o projeto tenha atingido bons resultados foi descontinuado em 1999, não existindo nenhuma versão do software disponível. É provável que a interrupção do projeto tenha ocorrido em função das restrições tecnológicas da época já que o acesso a equipamentos de gravação de vídeo digital era ainda bastante restrito se comparado ao acesso nos dias de hoje.

Considerando as condições atuais - popularização da produção de vídeos e maior facilidade de acesso a equipamentos de gravação de vídeos - bem como o potencial educacional dessa 
atividade, é que foi desenvolvido o protótipo do Promídia ${ }^{1}$, um software educacional destinado a auxiliar o processo de produção de vídeos por crianças e adolescentes.

\section{O Promídia}

O Promídia foi desenvolvido com o objetivo de dar suporte às atividades desenvolvidas nas etapas de pré-produção e pós-produção de um vídeo, oferecendo ao usuário uma visão geral de todo o processo. Tal visão, como foi dito, facilita o desenvolvimento da produção e visa também auxiliar na aprendizagem do processo e de suas características. Além disso, centralizando todos os artefatos gerados durante a produção de um vídeo (textos, imagens, vídeos, etc.) em um único ambiente, procuramos facilitar a organização da produção.

No design da interface do Promídia procuramos representar as cinco principais atividades da produção de um vídeo: a Sinopse, o Roteiro, o Storyboard, a Edição e a Apresentação. A Figura 1 ilustra a interface do Promídia, na qual destaca-se a Barra de Navegação (1a), que tem o objetivo de representar essas etapas, estando cada uma delas associada a um módulo do Promídia. O usuário pode navegar entre os módulos pressionando o botão que representa a etapa para a qual deseja ir. Dessa forma, o usuário tem a visão de todo o processo, pois esta Barra de Navegação é visível em todos os módulos e funciona como ponto central do usuário no sistema.

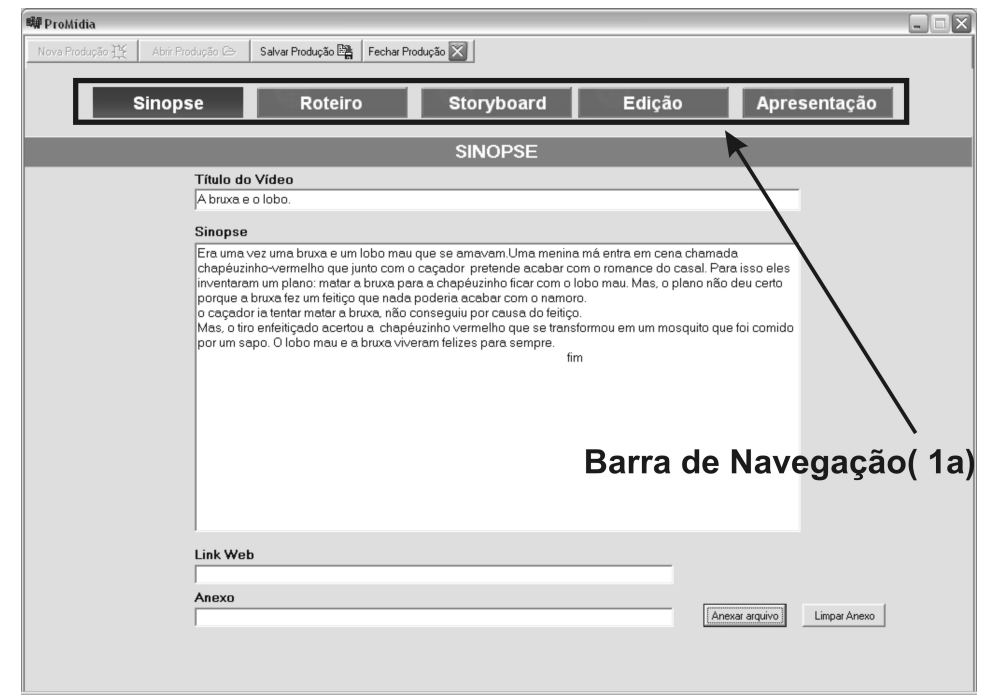

Figura 1. Módulo Sinopse.

Supondo que a produção do vídeo se dê de maneira linear a primeira atividade é o desenvolvimento da sinopse - elaborada a partir da idéia inicial do vídeo - representada no módulo Sinopse, conforme ilustra a Figura 1.

Após a sinopse, em geral, se desenvolve um argumento, isto é, o detalhamento do que vai acontecer no vídeo. Como o argumento é um passo intermediário entre a sinopse e o roteiro, julgamos que a sua representação no Promídia não seria tão relevante, já que o roteiro dispõe dos elementos existentes no argumento. Dessa maneira, incluímos no módulo Roteiro da ferramenta essa etapa de desenvolvimento que detalha tudo que será apresentado no vídeo. A Figura 2 ilustra a interface do módulo Roteiro. Nesse módulo o roteiro é dividido em cenas que têm os seguintes elementos do formato Master Scenes (Vargas, 2007):

- Cabeçalho;

- Ações (ou descrições de cena);

- Falas (que compõem os diálogos);

\footnotetext{
1 - O Promídia foi desenvolvido como parte da dissertação de mestrado de Ariel Vargas (Vargas, 2007), sob orientação da Profa. Dra. Heloísa Vieira da Rocha.
} 


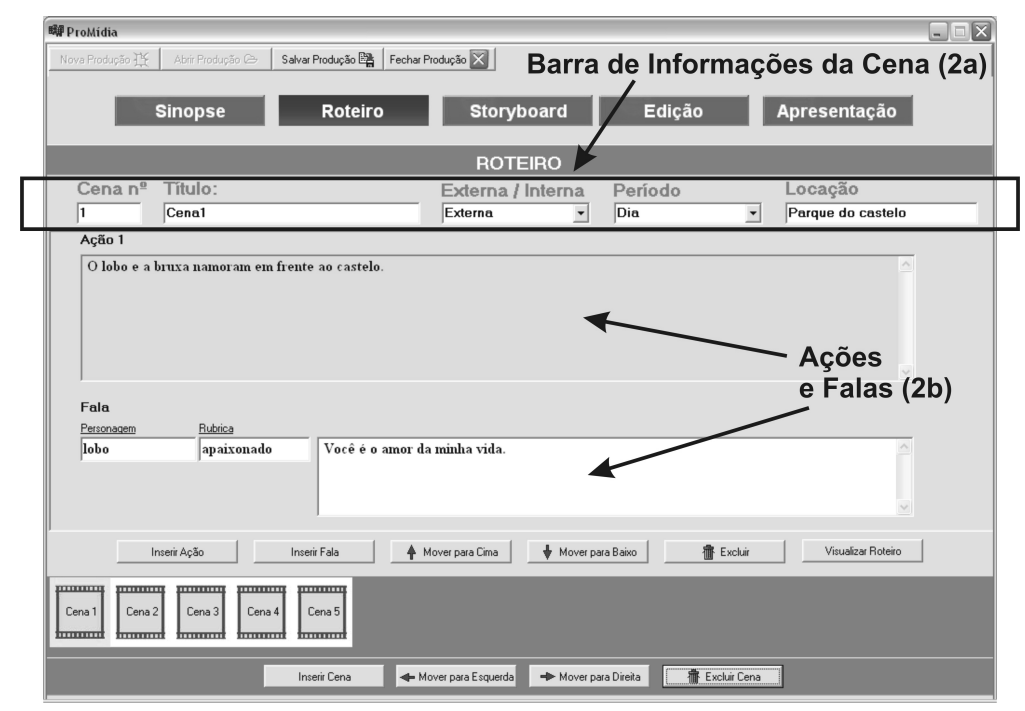

Figura 2. Módulo Roteiro.

O cabeçalho é representado na interface pelas informações constantes na Barra de Informações de Cena (2a), conforme ilustra a Figura 2. Essas informações refletem o cabeçalho da cena no roteiro. Além das informações do cabeçalho o usuário compõe seu roteiro inserindo "Ações" e "Falas" (2b), conforme ilustrado na Figura 2. As "Ações" contém as descrições da cena e do que nela acontece. Não incluímos como funcionalidades do módulo Roteiro elementos que se referem a detalhes de som, transição de cenas, enquadramentos ou movimentos de câmera. No entanto, essas informações podem ser inseridas pelo usuário no campo "Ação", na forma de descrição textual. Dessa maneira, evitamos que usuários iniciantes necessariamente tenham que informar esses elementos e, ao mesmo tempo, possibilitamos que usuários mais experientes façam uso deles se assim o desejarem. No módulo Roteiro é possível ainda visualizar o roteiro completo, conforme ilustra a Figura 3.

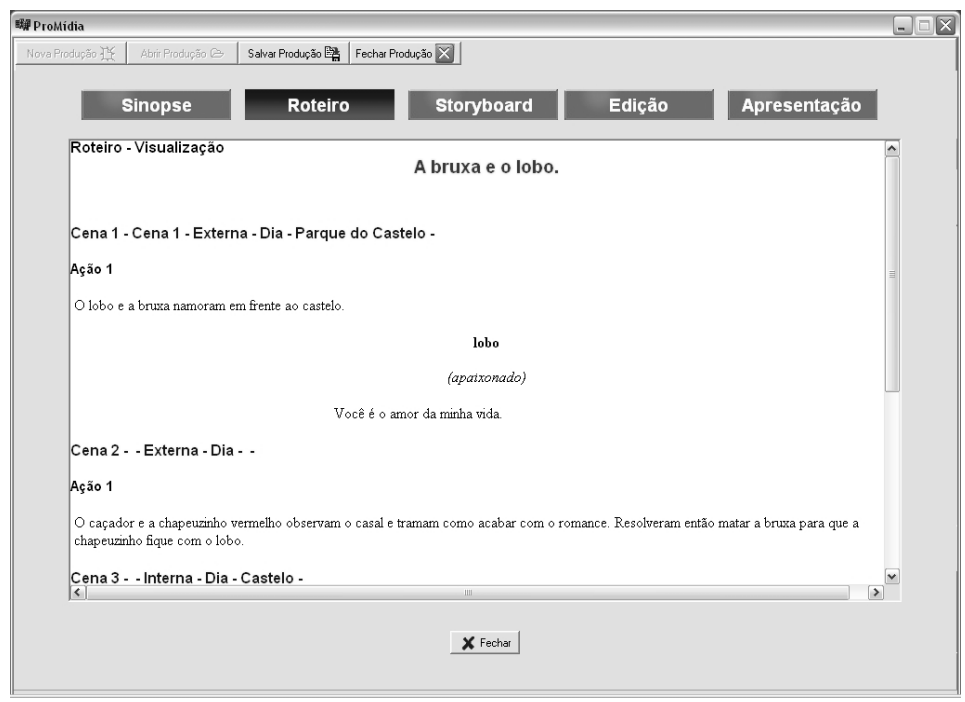

Figura 3. Visualização do roteiro completo.

Feito o roteiro, geralmente, se desenvolve o storyboard de algumas cenas, ou de todo o vídeo, com o objetivo de ilustrar e permitir sua visualização prévia por parte da equipe de produção. Essa etapa é representada no módulo Storyboard conforme ilustra a Figura 4, onde os usuários concretizam na forma de desenhos o que vai acontecer nas cenas.

A composição do storyboard é feita por meio da inserção de imagens sendo necessário, assim, importar arquivos de imagens para a ferramenta. Nessa primeira versão do Promídia 
optamos por essa solução visando dar liberdade e flexibilidade ao usuário para decidir como farão os desenhos de suas cenas. Em versões futuras pretendemos incluir outras formas de composição de storyboards.

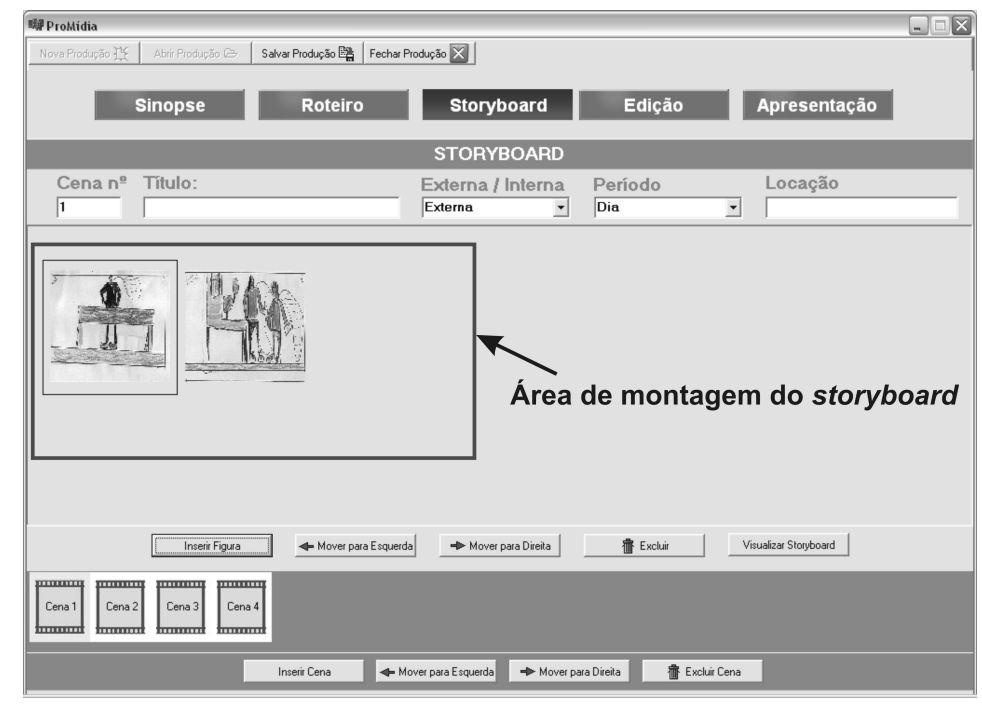

Figura 4. Módulo Storyboard.

Essas três atividades, portanto, representam, na ferramenta, a etapa de pré-produção de um vídeo. A etapa de pós-produção foi representada pelas atividades de Edição e Apresentação em seus respectivos módulos. Na Edição o usuário faz a montagem de seu vídeo com base nas cenas filmadas e por meio do módulo Apresentação pode visualizar o resultado final e completo do trabalho.

No módulo Edição - tendo as cenas já gravadas em arquivos - o usuário faz a montagem do vídeo (conforme ilustra a Figura 5) que consiste, basicamente, na importação e encadeamento dos arquivos que contém os trechos gravados. Nessa versão do protótipo não chegaram a ser implementados recursos de edição como cortes e aplicação de efeitos nas cenas; tais funcionalidades serão incorporadas nas versões futuras do software.

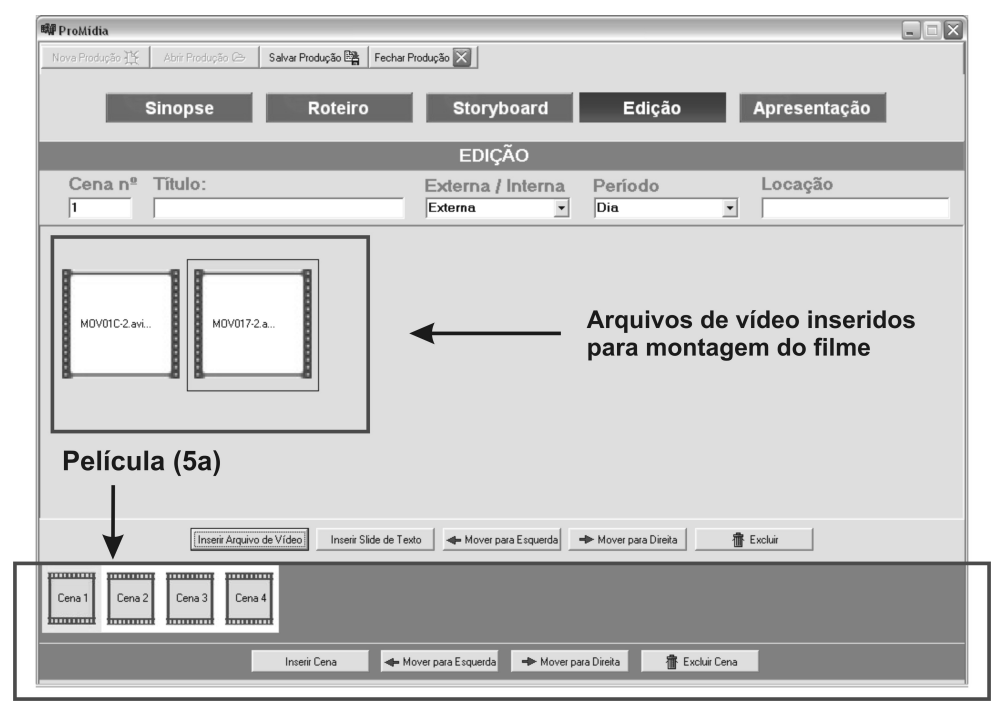

Figura 5. Módulo Edição.

Os módulos Roteiro, Storyboard e Edição têm um elemento comum - a Película (5a) conforme ilustra a Figura 5. A Película está presente na parte inferior de cada módulo, e funciona como meio de localizar e navegar entre as cenas.

Como esses módulos são divididos em cenas e toda a interação por meio deles baseada em 
cenas , ao se inserir uma determinada cena ela é automaticamente inserida nos três módulos. Da mesma forma, se uma cena é excluída, é excluída dos três módulos. Em outras palavras, inspirado na ferramenta MAD (Rosenthal \& Baecker, 1994), o Promídia permite que uma mesma cena seja visualizada de diferentes formas. O design da interface foi planejado dessa forma para facilitar ao usuário relacionar a mesma cena nos três módulos.

Por fim, no módulo Apresentação, pode-se visualizar o vídeo produzido. Esse módulo tem as funções básicas para a exibição do vídeo: exibir, pausa, avançar, retroceder e parar, conforme ilustra a Figura 6.

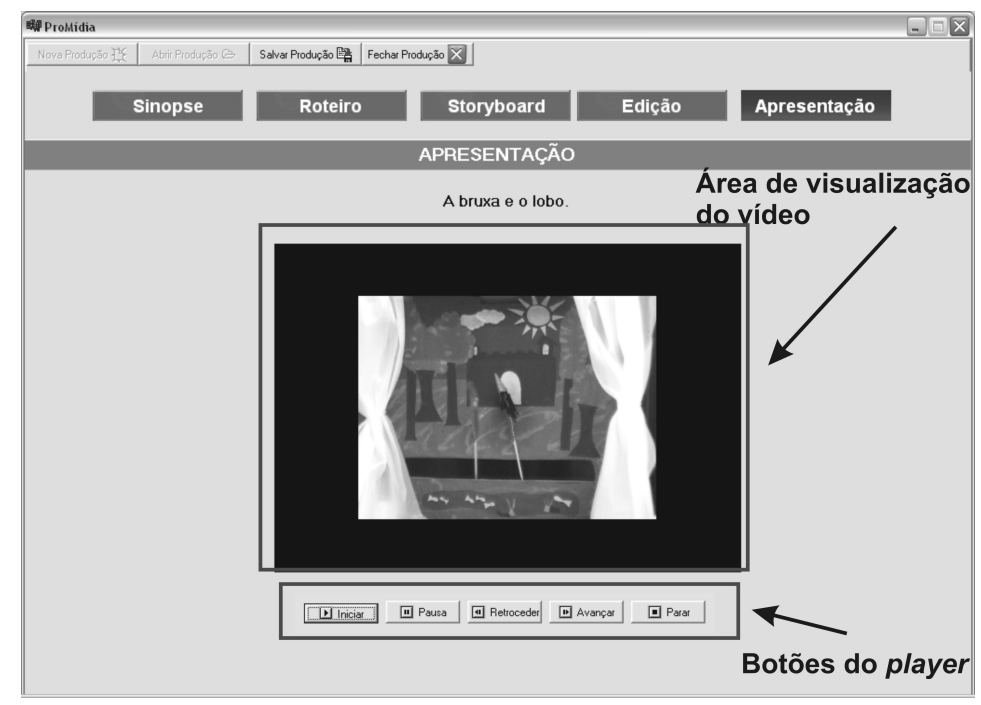

Figura 6. Módulo Apresentação.

Uma das principais preocupações no design da interface do Promídia foi desenvolvê-la de modo que ela favorecesse tanto a interação dos usuários menos familiarizados com a atividade de produção de vídeos, quanto a interação daqueles que são mais experientes.

Visando auxiliar os usuários menos experientes, a interface possibilita que o processo seja realizado de maneira linear, passo a passo, facilitando o desenvolvimento (e entendimento) da atividade por alunos que nunca fizeram um vídeo. Esses usuários podem desenvolver a produção começando pela escrita da sinopse, passando pela escrita do roteiro, desenvolvimento do storyboard, filmagens, montagem do filme e, finalmente, sua exibição.

Pensando nos usuários mais experientes, a interface do Promídia permite que seja desenvolvida qualquer uma das etapas, em qualquer ordem. Todos os módulos são relacionados entre si, no entanto, não é obrigatório que o usuário use todos os módulos e nem que realize uma sequiência específica de passos. Assim, esperamos prover maior flexibilidade de uso para os usuários mais experientes permitindo que desenvolvam as etapas que desejarem na ordem que quiserem, dando-lhe total liberdade de navegação nos módulos da ferramenta. Durante o design da interface também tivemos a preocupação de manter um padrão de interação e funcionalidades entre os módulos visando aumentar a usabilidade. Além disso, tentamos manter a interface minimalista, mantendo visíveis apenas os elementos e funcionalidades essenciais.

\section{Testes do protótipo}

Com o primeiro protótipo do Promídia realizamos dois testes com usuários. O primeiro teste foi desenvolvido com alunos com idades entre 10 e 16 anos que cursavam o ensino fundamental, o público-alvo do software. O segundo teste foi realizado com alunos do último ano do curso de Midialogia da Unicamp. A seguir, descrevemos cada um deles e seus resultados

\subsection{Primeiro Teste}

O primeiro teste foi feito com um grupo de 7 alunos com idades entre 10 e 16 anos que 
freqüentam o Centro de Convivência de Linguagens (CCAzinho) do Instituto de Estudos da Linguagem (IEL) da UNICAMP, sob responsabilidade da Profa. Dra. Maria Irma Hadler Coudry. Dele participam, além das crianças e jovens, alunos de graduação e pós-graduação dos cursos de Letras, Lingüística e Fonoaudiologia da Universidade.

O CCAzinho desenvolve atividades com alunos de escolas de Campinas que apresentam em comum dificuldades relacionadas à aquisição e ao uso da escrita . Cada um dos sete alunos participantes do teste apresenta também algum outro tipo de dificuldade como baixa audição e problemas de fala. Um deles, vítima de um acidente que lhe causou uma lesão cerebral, apresenta perda parcial dos movimentos de um lado do corpo e problemas de memória.

Optamos pela realização dos testes com esses alunos dada a heterogeneidade do grupo várias idades, perfis e histórias de vida diferentes, níveis sócio-culturais variados, diferentes níveis de acesso à tecnologia e, portanto, de letramento digital - o que nos permitiria observar e analisar uma ampla gama de possibilidades de interação com a ferramenta, bem como pelo potencial que a ferramenta representa no trabalho com a linguagem desses alunos, foco do trabalho que se faz no CCAzinho.

Nos testes, além dos alunos, participaram dois professores e sete alunos de graduação e mestrado, que já trabalhavam com eles em outras atividades, atuando como monitores. Nesse teste estabelecemos os seguintes objetivos:

- Verificar como seria o transcorrer de uma atividade de produção de vídeos, desenvolvida por crianças em um ambiente educacional. Pretendia-se verificar na prática o potencial educacional descrito na literatura.

- Verificar a adequação do software desenvolvido como ferramenta de apoio ao processo de produção de vídeos. Ou seja, verificar se a ferramenta oferecia o suporte necessário às etapas da produção de um vídeo.

- Testar a usabilidade da interface da ferramenta, analisando se as decisões tomadas no design da interface estavam adequadas ou se apresentavam problemas a ser corrigidos.

\subsubsection{Desenvolvimento do primeiro teste}

A atividade de teste com os usuários foi desenvolvida visando que os alunos realizassem todas as etapas da produção de um vídeo, desde a concepção da idéia, até sua filmagem e finalização, utilizando o protótipo do Promídia. Planejamos a atividade para que fosse executada em passos - já que todos eram inexperientes em relação à produção de vídeos - , de maneira interativa e prática de modo que os aspectos técnicos (uso do software) e teóricos (etapas da produção propriamente dita) que seriam aprendidos ao longo da execução da atividade fossem a eles apresentados de forma integrada e contextualizada. Feita a apresentação da proposta de trabalho ao grupo de alunos organizamos os trabalhos ao longo de seis semanas, com uma sessão semanal, com duração de duas horas. Dividimos a atividade de forma que a cada sessão os alunos trabalhassem em uma etapa da produção do vídeo, refletida na interface da ferramenta.

- $\quad \mathbf{1}^{\text {a }}$ sessão: Sinopse - As crianças foram divididas em duas equipes de três e de quatro alunos e elaboraram a sinopse do vídeo a ser produzido por cada uma delas. Uma equipe escolheu produzir um comercial de televisão e a outra um filme com bonecos de fantoche. Esta atividade foi antecedida pela discussão e definição dos temas, até que atingissem uma idéia consensual que resultou em um breve resumo contendo a idéia geral de cada vídeo.

- $2^{\text {a }}$ sessão: Roteiro - Apresentamos aos alunos o conceito de roteiros, explicando quais são os seus elementos e características. A partir daí os alunos desenvolveram o roteiro de seus vídeos usando o Promídia.

- $3^{\text {a }}$ sessão: Storyboard - Apresentamos aos alunos o conceito de storyboard. Para tanto, utilizamos como exemplo uma história em quadrinhos explicando que o storyboard consiste em uma representação do roteiro feita na forma de desenhos, semelhante a uma uma história em quadrinhos. Os alunos, então, fizeram os desenhos para compor o 
storyboard dos vídeos. Os desenhos das equipes foram recolhidos para serem digitalizados.

- $\quad 4^{\text {a }}$ sessão: Montagem do storyboard e ensaio - Os alunos realizaram a montagem do storyboard no Promídia utilizando os desenhos que eles haviam feito e que haviam sido digitalizados. Cada equipe também realizou o ensaio para a gravação das cenas do vídeo, que aconteceria na sessão seguinte.

- $\quad 5^{\mathbf{a}}$ sessão: Filmagem - As filmagens foram feitas com aos alunos atuando e operando a câmera. Em alguns momentos, quando os alunos estavam todos envolvidos atuando, as monitoras ajudavam com a câmera. Ao final da quinta sessão, ambas as equipes haviam conseguido realizar a filmagem de todas as cenas dos vídeos.

- $\quad$ 6 $^{\text {a }}$ sessão: Montagem e Apresentação - As equipes realizaram a montagem do seu vídeo utilizando as filmagens gravadas. Cada arquivo possuía uma cena ou trecho de cena, com as quais os alunos montaram a seqüência que compunha o vídeo. Terminada essa etapa utilizamos um projetor para que os alunos apresentassem para o restante do grupo o resultado de sua produção.

Findo o teste propriamente dito fizemos uma reunião com os professores que participaram da atividade com o objetivo de obter a percepção deles em relação ao trabalho desenvolvido. Além disso, para coletar os dados da interação dos alunos com o Promídia, utilizamos um software de captura, que grava em áudio e vídeo a interação. Durante as atividades também eram feitas anotações a respeito do comportamento, dos comentários e das reações dos alunos. Durante a realização das diferentes tarefas do teste, acompanhamos os alunos visando registrar quaisquer dúvidas ou dificuldades que eles pudessem encontrar. Além disso, todas as sessões foram filmadas com a finalidade de se poder rever os vídeos a fim de recuperar os eventos ocorridos ao longo do teste.

\subsubsection{Resultados do primeiro teste}

A partir dos dados coletados durante a atividade foi possível realizar uma análise dos resultados podendo-se identificar aspectos que apontam para o potencial que a produção de vídeos realizada como atividade educacional apresenta, destacando-se:

Motivação - Um dos primeiros aspectos observáveis na atividade foi a motivação que desperta nos alunos, conforme descrições de Martiani (1998), Moran (1995), Behmer (2006), Shewbridge \& Berge (2004), Ellis et al. (2004), Christie (2006). A percepção da motivação dos alunos foi observada durante toda a atividade e confirmada na fala dos professores que dela participaram. Eles relataram que estavam muito surpresos com a vontade que os alunos demonstraram em participar de todas as etapas. Um dos comentários foi "Fiquei impressionada em ver a vontade de uma das crianças na hora de utilizar o computador. Eu não esperava que ela tivesse essa disposição. Apesar de ter dificuldades na escrita, ela ficou muito entusiasmada em escrever a sinopse e o roteiro no software. Em nenhum momento ela falou que queria parar ou sair do computador, como acontece geralmente em outras atividades “ (Vargas, 2007). Além disso, esse mesmo aluno demonstrou grande disposição em participar das filmagens, atitude que surpreendeu os professores, pois geralmente ele não se engaja com facilidade nas atividades propostas.

Autoconfiança - Outro fator observado foi a perda da timidez e aumento da autoconfiança, que freqüentemente ocorrem nesse tipo de atividade, conforme Monteiro (2006), Shewbridge \& Berge (2004), Ellis et al. (2004). Um dos professores fez o seguinte comentário: "Eu fiquei impressionada com a aluna que geralmente é muito severa no julgamento das coisas que produz. Eu achei que ela não ia querer participar das filmagens, por saber que depois seria vista na tela. Me espantou a disposição dela em participar. Acho que a atividade deu mais segurança para os alunos em se expor na realização de algo, sem tanto medo de errar."

Integração de capacidades - Tanto Martiani (1998), quanto Behmer (2006) enfatizam que a produção de vídeos por crianças desperta habilidades, inteligências e aptidões múltiplas, por se tratar de uma atividade multidisciplinar. Um dos professores comentou que esse 
desenvolvimento múltiplo ficou bastante evidente no decorrer da atividade: "Eu achei que a produção do filme foi uma forma muito interessante de desenvolvimento global dos alunos, porque eles passaram por todo um processo, no qual, usaram a leitura, a escrita, interagiram com o computador, desenharam, elaboraram uma história, transformaram num roteiro, num storyboard e depois materializaram isso tudo atuando na frente da câmera. Como forma de desenvolvimento global eu achei excelente".

Trabalho em equipe - Martiani (1998) e Shewbridge \& Berge (2004) ressaltam que um dos benefícios da atividade de produção de vídeos, por ser um trabalho desenvolvido em equipe, é a valorização do trabalho de grupo e a interação social. Essa valorização do trabalho da equipe pode ser observada quando, no dia das filmagens, dois alunos não puderam comparecer. No entanto, a falta dos dois alunos foi contornada com a participação dos outros alunos, fazendo com que as equipes se misturassem, cooperando uma com a outra. Isso confirma a fala de Martiani (1998) que afirma que a produção de vídeos é uma atividade onde os alunos atuam de forma colaborativa, estimulando a interação e o entrosamento com o objetivo de realizar as tarefas propostas.

Compreensão global do processo - Outro fator interessante ocorrido durante a atividade foi perceber a compreensão do processo de produção pelos alunos. Pode-se verificar que eles estavam entendendo e conseguindo encadear as etapas do processo. Por exemplo, após a apresentação do conceito de storyboard aos alunos, um deles, ao folhear uma das revistas em quadrinhos utilizadas como exemplo, encontrou uma história igual a um desenho animado que já havia assistido. Ele comentou então, que aquela história em quadrinhos poderia ser o storyboard que deu origem ao desenho animado que ele havia visto. Dessa forma, pode-se perceber que o aluno conseguiu relacionar as etapas da produção que eles mesmos estavam vivenciando. Um dos professores comentou ainda que os alunos, em geral, tinham dificuldades, ao escrever textos, de estabelecer uma estrutura lógica-argumentativa das idéias de modo a organizar o texto. O professor comentou: "A atividade foi interessante porque ela teve um começo, um meio e um fim. E depois, no programa, eles puderam visualizar melhor essa estrutura, identificando as etapas que passaram para chegar ao resultado final, que é o filme. Com a ajuda do software eles puderam ter uma visão completa do processo de criação do seu filme". Outro professor acrescentou: "A produção do vídeo foi interessante, pois foi uma maneira concreta de estruturar o pensamento deles, o que geralmente é mais difícil quando eles estão apenas produzindo textos".

Através dos resultados relatados anteriormente pode-se observar que a atividade de produção de vídeos em um ambiente educacional é uma atividade viável e com grande potencial educacional. Pode-se perceber também que as dificuldades que os alunos participantes do experimento apresentavam não impediram que eles desenvolvessem as atividades, tampouco influenciaram negativamente em seus desempenhos. Isso indica que a atividade não tem restrições de público e pode ser indicada para os mais variados contextos educacionais, com diferentes propósitos.

Além disso, percebeu-se que o protótipo do Promídia teve êxito em auxiliar o processo de produção, contribuído para o trabalho dos alunos e, também, para a compreensão do processo. $\mathrm{O}$ software facilitou a conexão das etapas desenvolvidas, cumprindo o papel para o qual foi planejado. Em relação à usabilidade da ferramenta não foram encontrados problemas graves de usabilidade que pudessem dificultar sua utilização no desenvolvimento das atividades, mas sim, observamos possibilidades de melhorias a serem implementadas em trabalhos futuros.

\subsection{Segundo Teste}

O segundo teste foi desenvolvido com quatro alunos do Curso de Midialogia da UNICAMP com idades entre 19 e 22 anos que estavam no último ano do curso. Apesar de não fazerem parte do público-alvo do Promídia, esses alunos costumam produzir vídeos em suas atividades acadêmicas, tendo conhecimento sobre o processo de produção de vídeos e características da linguagem áudio-visual. Dessa maneira, achamos interessante testar o Promídia com esse público já que eles podem contribuir com sugestões e com a validação das idéias implementadas no Promídia. 


\subsubsection{Desenvolvimento do segundo teste}

O segundo teste foi realizado em duas sessões, com cerca de 2 horas de duração cada, em virtude da disponibilidade do grupo de alunos. Na primeira sessão apresentamos o protótipo do Promídia aos alunos e à professora da disciplina Tópicos Especiais em Midialogia III, explicando-lhes o contexto para o qual havia sido desenvolvido e quais seus objetivos. A impressão inicial geral do grupo foi a de que a ferramenta poderia facilitar o a produção de roteiros.

Na segunda sessão os alunos utilizaram o protótipo do Promídia para elaborar o roteiro de um vídeo. Durante a utilização do Promídia pelos alunos observamos o comportamento dos usuários e registramos seus comentários. Ao final do teste os alunos responderam a um questionário com o objetivo de obtermos dados sobre a percepção do grupo em relação ao software e à interação com ele.

\subsubsection{Resultados do segundo teste}

Analisando-se os dados dos questionários, comentários dos alunos e o seu comportamento ao longo da atividade pudemos verificar que o Promídia foi bem aceito pelo grupo e esteve de acordo com suas expectativas. Além disso, os alunos acharam que a interface do software estava adequada à linguagem audiovisual, além de ser bastante fácil de ser utilizada. Alguns comentários dos alunos foram:

"Acho que o software é bastante claro e que uma breve explicação inicial já permitiria que alguém que não tivesse experiência utilizasse-o tranqüilamente".

"O software é bastante interessante e facilita bastante no processo de produção de um roteiro, além de ser uma ferramenta prática para o aprendizado do público infantil, alvo do produto”.

"Achei muito interessante trabalhar com ele porque é simples, pode ser usado por crianças, mas acredito que seja bastante útil para profissionais também, principalmente por formatar o roteiro. Acho que poderia existir a opção de salvar entre as cenas.”

Não se encontrou também nenhum problema de usabilidade que dificultasse ou impedisse a utilização do software pelos alunos, eles se restringiram a fazer algumas sugestões.

Foi também interessante verificar, através desse teste, que apesar de o software ter sido planejado para um público de crianças e adolescentes foi útil para usuários adultos, mais experientes em produção de vídeos. Outro ponto relevante foi a aprovação da interface pelos usuários, observável na fala de um dos alunos: "Achei muito interessante trabalhar com ele porque é simples". A afirmação do aluno valida a estratégia adotada em desenvolver a interface para ser simples, apenas com os recursos, informações e funcionalidades essenciais, como as quais, mesmo usuários inexperientes, podem interagir.

\section{Conclusões}

Nos dias de hoje, com a popularização dos equipamentos para gravação de vídeos, computadores e sites para disponibilização de vídeos na Internet, é bastante crescente o interesse e a disposição de crianças e adolescentes, não apenas em serem consumidores, mas também em serem produtores desse tipo de mídia.

Conforme relatado na literatura e observado durante as atividades de teste realizadas com o Promídia, a atividade de produção de vídeos tem grande potencial educacional. Desse modo, acredita-se que o Promídia pode auxiliar no desenvolvimento dessas atividades e permitir a exploração desse potencial em atividades educacionais.

\subsection{Trabalhos futuros}

Como trabalhos futuros pretendemos desenvolver uma versão final do Promídia, já que até o momento apenas um protótipo para testes foi desenvolvido. Nessa versão pretendemos incluir algumas novas funcionalidades sugeridas pelos usuários que participaram dos testes, bem como outras decorrentes de nossas observações feitas. . 
Pretendemos ainda disponibilizar o Promídia gratuitamente e acompanhar sua utilização em algumas escolas visando obter o feedback dos usuários em situações cotidianas de utilização.

\section{Referências Bibliográficas}

ADOBE SYSTEMS INCORPORATED. Adobe Premiere. Disponível em:

<http://www.adobe.com/products/premiere/>. Acesso: dezembro/2006.

APPLE COMPUTER INC. Apple - iLife - iMovie.

Disponível em: http://www.apple.com/ilife/imovie/. Acesso em: junho/2006.

BAECKER, R.; POSNER, I. Children As Digital Motion Picture Authors. In: DRUIN, A. The Design of Children's Technology, Morgan Kaufmann, 1999, 169-200.

BAECKER, R.; ROSENTHAL, A. J.; FRIEDLANDER, N.; SMITH, E.; COHEN, A. A Multimedia System for Authoring Motion Pictures. In: ACM Multimedia 96, Bostom, MA, USA. 1996. p.31-42.

BEHMER, S. Literature Review Digital storytelling: Examining the process with middle school students. 2005. Disponível em: < http://projects.educ.iastate.edu/ ds/Behmer/LitReview.pdf > Acesso em: maio/2006.

CHRISTIE, A. A. Language Arts Comes Alive as Middle School Learners Become Information Producers. Meridian: A Middle School Computer Technologies Journal - a service of NC State University, Raleigh, NC. Volume 7, Issue 1, Winter 2004.

ELLIS, G. W.; LEE, K. S.; THAM, A. Learning Engineering Mechanics Through Video Production. In: 34th ASEE/IEEE Frontiers in Education Conference, Savannah, GA, October 20 - 23, 2004, Session F4E.

FINAL DRAFT INC. Final Draft. 2006. Disponível em: <http://www.finaldraft.com/>. Acesso em: Dezembro/2006.

KINDEM, G.; MUSBURGER, R. B. Introduction to Media Production: from analog to digital. Focal Press, Bostom, 1997.

MARTIANI, L. A. O vídeo e a pedagogia da comunicação no ensino universitário. In: PENTEADO, H. L. Pedagogia da comunicação - Teorias e Práticas. Ed. Cortez, 1998. p. 151 - 195.

MICROSOFT CORPORATION. Windows Movie Maker. 2006

Disponível em: <http://www.microsoft.com/windowsxp/using/moviemaker/default.mspx>. Acesso em: dezembro/2006.

MONTEIRO, E. O Que Crianças e Professores são Capazes de Fazer Com: uma idéia na cabeça e uma câmera na mão. Disponível em:

$<$ http://scholar.google.com.br/url?sa=U\&q=http://www.eca.usp.br/nucleos/nce/pdf/041.pdf> Acesso em: março/2006.

MORAN, J. M. O Vídeo na Sala de Aula. Comunicação \& Educação. São Paulo, ECA-Ed. Moderna, [2]: 27 a 35, jan./abr. de 1995.

POSNER, I.; BAECKER, R.; HOMER, B. Children Learning Filmmaking Using Multimedia Tools. In: Ed-Media'97. 1997.

POWERPRODUCTION SOFTWARE. Storyboard Quick. 2006. Disponível em:

$<$ http://www.powerproduction.com/home.html>. Acesso em: dezembro/2006.

ROSENTHAL, A. J.; BAECKER, R. M. Multimedia for Authoring Motion Pictures. Graphics Interface'94. Proceedings. 1994. p. 133-140.

SHEWBRIDGE, W.; BERGE, Z. L. The role of theory and technology in learning video production: the challenge of change. International Journal on E-Learning, 3.1, p. 31-39, jan/mar. 2004. 
SIX MILE CREEK SYSTEMS. SpringBoard. 2006

Disponível em: <http://6sys.com/Springboard/>. Acesso em: dezembro/2006.

VARGAS, A. Desenvolvimento de um Software Educacional para Auxílio à Produção de Vídeos. Dissertação (Mestrado em Ciência da Computação). Instituto de Computação - Universidade Estadual de Campinas, Campinas SP, 2007.

WRITE BROTHERS INC. Movie Magic Screenwriter. 2006.

Disponível em: <http://www.screenplay.com/products/mms/index.htm>.

Acesso em: dezembro/2006. 